\title{
Plasmapheresis therapy for immune-mediated diseases in neurology: literature review
}

\author{
Francisco Tomaz Meneses de Oliveira*, Natália Corrêa De Luca, and Charles Peter Tilbery
}

Department of Neurology, Santa Casa, São Paulo-SP, Brazil

\begin{abstract}
Plasmapheresis is a therapeutic apheresis procedure of high complexity, often available only in reference centers. This availability allows the medical team to offer the patient a treatment that has been proven effective for morbidities of major impact from the clinical point of view, reflecting directly on the patient's quality of life. This literature review shows that many immune-mediated neurological diseases have satisfactory therapeutic response to this procedure. Myasthenia gravis, chronic demyelinating inflammatory polyradiculoneuropathy, Guillain-Barré syndrome and multiple sclerosis are the main representatives.
\end{abstract}

\section{Introduction}

Plasmapheresis is a procedure which may be used therapeutically or just to collect material for transfusion. When therapeutic, it separates the patient's blood components replacing the plasma removed by a donor fluid, colloid or crystalloid, usually albumin or saline solution $[1,2]$. Historically, large amounts of plasma could only be exchanged via manual phlebotomy followed by centrifugation, a slow and complicated technique, which generally only allowed exchange of $500 \mathrm{ml}$ per session [2].

It is nowadays a highly complex procedure, often available only in reference centers. The availability enables the medical staff to offer the patient an effective proven treatment to morbidities of great impact from the clinical point of view. The pathogenic substance may be an autoantibody, circulating immune complexes, lipoproteins, endotoxins, among others. The molecule should be large and long half-life for a removal faster than its endogenous clearance, and it has to be acutely toxic and / or resistant to conventional therapies so that the procedure is suitably indicated [3]. The most common adverse effect is hemodynamic instability. A careful evaluation of the impact of this procedure must be done before treatment with clinical and laboratory tests.

There are various immune mediated neurological pathologies belonging to the group of diseases in which plasmapheresis is indicated. In myasthenia gravis and chronic inflammatory demyelinating polyradiculoneuropathy it is considered a first line treatment [4], but there are still many other neurological morbid conditions in which the patient can get enough benefits, even when it is not considered firstline therapy.

The Canadian Apheresis Group (CAG) published a work at 1999 demonstrating an increase in the number of indications. In 1981 there were 3,189 sessions carried by this group while 8,208 in 1997. In addition, only $50 \%$ of the main indications of this therapy had published scientific evidence at 1981, which rose to $100 \%$ in 1997 [5].

Thus, the issue becomes important to register the clear indications of this treatment, as well as demonstrate the variability of diseases that can benefit from it.

\section{Methodology}

This literature review was conducted searching in the database MEDLINE ${ }^{\oplus}$, LILACS $^{\star}$ and PubMed ${ }^{\circledR}$, with the following descriptors: "Plasmapheresis and neurology", "Plasmapheresis and myasthenia", "Plasmapheresis and polyradiculoneuropathy" in LILACS", "Plasmapheresis and neurologic disorders", "Plasmapheresis and miyasthenia", "Plasmapheresis and chronic inflammatory demyelynating polyneuropathy," "Plasmapheresis and multiple sclerosis" in PubMed ${ }^{\circledR}$ and MEDLINE .

Immune-mediated neurological diseases and plasmapheresis

The neurological diseases most treated with plasmapheresis include Guillain-Barré syndrome, acute onset polyradiculoneuropathy, single and autoimune, including axonal variants and the Miller Fisher variant [4]. Clinical presentation is progressive weakness of acute onset of members, usually distal and symmetrical, with hyporeflexia or areflexia. The progression is rapid, with possible involvement of cranial nerves, weakness of the diaphragmatic muscle and disautonomic disorders. One third of these hospitalized patients will develop requiring mechanical ventilation $[4,6]$.

Plasmapheresis and intravenous immunoglobulin are the best treatments. Several studies have demonstrated significant improvement in symptoms with the use of plasmapheresis. The clinical decision is individualized, according to the availability of these treatments and adverse effect profile [6]. Nogales-Gaete et al. in a retrospective study of 159 procedures in 54 patients between 1995 and 2001 at a Neurology Service in Chile, showed that $88 \%$ of these procedures were indicated for neurological disorders, and Guillain Barré syndrome was the most frequent one, with $35.1 \%$ of the procedures performed for this condition. In Turkey, Yücesan et al. [7] conducted a review

Correspondence to: Francisco Tomaz Meneses de Oliveira - Rua Dr Cesario Mota Jr, 112 - Vila Buarque, São Paulo-SP, Brasil, E-mail: towmaz@gmail.com

Key words: plasmapheresis, neurological diseases, immune-mediated

Received: February 25, 2016; Accepted: May 03, 2016; Published: May 06, 2016 
of 50 neurological cases between 1998 and 2000, the majority cases of myasthenia gravis. There was a good clinical response to the use of plasmapheresis in all 30 cases [7].

In chronic Inflammatory demyelinating polyneuropathy, an acquired autoimmune neuropathy, the evolution is insidious, with an incidence that increases with age, reaching up to 1.5 times more people over 65 [8]. It usually causes motor and sensory deficits mainly in the extremities. There are also autoantibodies involved as in Guillain-Barré syndrome, but treatment beyond plasmapheresis and immunoglobulin indicate the use of corticosteroids and immunosuppression (cyclosporin or azathioprine). In the study cited above from Nogales-Gaete [9], 24\% of the 140 procedures performed in neurological patients were chronic inflammatory demyelinating polyneuropathy (Table 1).

Myasthenia gravis (MG) is a neurological disease mainly characterized by fatigue, weakness and ocular involvement, manifesting with ptosis and diplopia. The estimated annual incidence is 10 to 20 new cases per one million, with a prevalence of 150 to 200 patients per million [10-12].

Within a year, MG patients will evolve with bulbar, respiratory, limbs and trunk involvement, featuring a general framework. Myasthenic crisis occurs in one third of patients presenting as respiratory weakness requiring mechanical ventilation. Treatment includes thymectomy, acetylcholinesterase inhibitors, corticosteroids, immunosuppressants, intravenous immunoglobulin and plasmapheresis. Plasmapheresis is indicated in pre- and post-operative period following thymectomy as well as in myasthenic crisis, with a difference in the degree of recommendation from some organs (Table 2). At 2013, Zhang et al. [13] published a case-control study conducted in 2010 at a hospital in China with a sample of 35 patients diagnosed with late-onset myasthenia gravis. In this study, the sample was divided into two groups, one group received double filtration plasmapheresis and corticosteroids with oral methylprednisolone (group A). The other group received only methylprednisolone (group B). The clinical remission time, as the time from start of treatment for clinical remission, was significantly lower in Group A than in Group B, besides a lower expression of autoantibodies, better clinical efficacy rate measured by the test MGQ (quantified myasthenia gravis), lower need for ventilatory support and shorter length of stay.

Multiple sclerosis and a neuromyelitis optica are diseases of the central nervous system, both inflammatory and demyelinating with different physiopathologic mechanisms. Multiple sclerosis affects often females between 20 and 40 years and has an estimated prevalence of two million people affected worldwide $[14,15]$. Although not yet determined, the mechanism that causes multiple sclerosis appears to be autoimmune in patients with a genetic predisposition and may be influenced by external factors [15]. Typically, the patient presents with episodes of remission interspersed with outbreaks, although several clinical patterns are described, including relapsing-remitting, primary progressive and secondary progressive [15] types of multiple sclerosis. The use of intravenous methylprednisolone in multiple sclerosis is usually effective to better symptoms in the acute phase, but apparently the long-term impact is not well established [15]. In addition, plasmapheresis is considered beneficial in patients with multiple sclerosis during crisis who have not responded to high-dose intravenous corticosteroids, a situation which has also been described to benefit patients with neuromyelitis optica.

In the case of multiple sclerosis, as pathogenesis involves an immunemediated cellular mechanism, plasmapheresis is not considered a longterm modifying therapeutic strategy. Several anti-myelin autoantibody have been reported in multiple sclerosis, but it is not yet known if their presence is associated with a primary pathogenic role, a secondary humoral response or a repair function remyelination / axonal protection [16]. Some studies show that, besides depletion of antibodies and other soluble factors in the blood, this process can change the frequency and phenotypic expression of the different populations from immune

Table 1. Considerations when evaluating a new patient for early therapeutic plasmapheresis [12].

\begin{tabular}{|l|l|}
\hline Considerations & Description \\
\hline Racional Analysis & $\begin{array}{l}\text { Based on estimated or defined diagnosis and history of present illness, the discussion may include a rational analysis of the procedure, taking into } \\
\text { account the results of published studies and specific risks of the patient about the procedure. }\end{array}$ \\
\hline Impact & The effect of plasmapheresis on the associated morbidities and current medications should be considered. \\
\hline Technical Questions & Technical aspects such as the type of anticoagulant, replacement solution, vascular access and total volume processed should be evaluated. \\
\hline Treatment Plan & The total number and range of apheresis should be evaluated. \\
\hline Clinical and/or laboratory target & $\begin{array}{l}\text { Clinical and / or laboratory parameters should be established to monitor the effectiveness of treatment. The criterion for discontinuation of therapy } \\
\text { should be discussed where appropriate. }\end{array}$ \\
\hline Time and place of beginning & $\begin{array}{l}\text { The acceptable time to start the apheresis should be based on clinical considerations (medical emergency, routine, emergency, etc.). The place where } \\
\text { the procedure will take place (intensive care unit, operating room, ward, etc.) should also be evaluated. When urgent and there is no possibility of } \\
\text { performing the procedure, consider removing the patient depending on his clinical status. }\end{array}$ \\
\hline
\end{tabular}

Table 2. Degrees of Recommendation [12].

\begin{tabular}{|c|c|c|}
\hline Degrees of recommendation & Description & The evidence methodological quality \\
\hline $1^{\mathrm{a}}$ & Strong recommendation and high-quality evidence & $\begin{array}{l}\text { Randomized clinical trials (RCTs) without important limitations or observational studies with } \\
\text { important evidence }\end{array}$ \\
\hline 1B & Strong recommendation and moderate-quality evidence & $\begin{array}{l}\text { ECA with important limitations (methodological errors, indirect or inaccurate, inconsistent } \\
\text { results) or observational studies with strong evidence }\end{array}$ \\
\hline $1 \mathrm{C}$ & $\begin{array}{l}\text { Strong recommendation and evidence of low to very } \\
\text { low quality }\end{array}$ & Observational studies or case series \\
\hline $2^{\mathrm{a}}$ & Weak recommendation and high-quality evidence & $\begin{array}{l}\text { Randomized clinical trials (RCTs) without important limitations or observational studies with } \\
\text { important evidence }\end{array}$ \\
\hline 2B & Weak recommendation and evidence of moderate quality & $\begin{array}{l}\text { ECA with important limitations (methodological errors, indirect or inaccurate, inconsistent } \\
\text { results) or observational studies with strong evidence }\end{array}$ \\
\hline $2 \mathrm{C}$ & $\begin{array}{l}\text { Weak recommendation and evidence of low to very low } \\
\text { quality }\end{array}$ & Observational studies or case series \\
\hline
\end{tabular}


cells [17]. This hypothesis still needs to be confirmed and it will have great impact on the assessment of long-term illness. The association of neuromyelitis optica with antiaquaporin 4 , has been reported with a detection rate that ranges from 33 to $91 \%$, generally with a specificity of more than $90 \%[15,18,19]$. Due to the presence of this well established autoantibody, therapeutic plasmapheresis has been indicated in several cases of optica neuromyelitis when there is failure in the use of corticosteroid therapy with intravenous methylprednisolone and is more effective when started early [16]. Furthermore, it is necessary to consider the need for administering drugs such as cyclophosphamide and azathioprine only after the procedure, since it will promote the removal of these immunosuppressants in serum.

The acute disseminated encephalomyelitis (ADEM) is also an inflammatory demyelinating disease of the central nervous system. Although the etiopathogenesis of ADEM is not well established, it is presumed to have an autoimmune mechanism as it commonly appears after an infectious event or after vaccination [20]. Since this is usually monophasic polysymptomatic multifocal of acute or subacute onset, the encephalopathy is a necessary condition for diagnosis [20]. The treatment of ADEM includes lifestyle modification measures, corticosteroids, intravenous immunoglobulin and plasmapheresis, which is a category IV according to the American Society for Apheresis (ASFA), as we shall see.

As previously mentioned, Cortese et al. [1] in 2011 published an evidence-based guideline by the American Academy of Neurology (AAN) in establishing plasmapheresis as treatment effectiveness established by Class I studies for Guillain-Barré syndrome and polyneuropathy chronic inflammatory demyelinating short-term management.

Included in Class I with probable effectiveness are the outbreak of multiple sclerosis resistant to corticosteroids, mild Guillain-Barré syndrome and polyneuropathy with gammopathy IgA / IgG. The class II effectively covers the central nervous system fulminant disease. MG preoperative of thymectomy and myasthenic crisis due to insufficient evidence are categorized in Class III, which includes Sydenham's chorea, Obsessive-Compulsive Disorders Acute and Tics associated with PANDAS (Neuropsychiatric Pediatric Autoimune Disorders Associated with Streptococcal Infection). The plasmapheresis has been proved ineffective for secondary progressive MS according to this study [1] and probably ineffective in neuropathy associated with IgM gammopathy. Regardless of indication, the number of sessions and volumes to be exchanged needs to be established by new research (Table 3) [1].

In 2013 Schwartz et al. [12] issued a directive by the American Society for Apheresis (ASFA) which divided indications for apheresis into 4 general categories; Class I corresponding to the conditions in which the plasmapheresis corresponds to the first-line treatment, the category II as treating the second line, class III when the role of

Table 3. Classes for classification procedures [21].

\begin{tabular}{|c|c|}
\hline Classes & \\
\hline Class I & $\begin{array}{l}\text { Conclusive evidence and / or general agreement that a given procedure is useful } \\
\text { and effective }\end{array}$ \\
\hline $\begin{array}{l}\text { Class II } \\
\text { IIA } \\
\text { IIB }\end{array}$ & $\begin{array}{l}\text { Conflicting evidence or divergence of views on the usefulness and effectiveness } \\
\text { of the procedure } \\
\text { Despite the divergence the weight of opinion / evidence tends to favor of } \\
\text { usefulness /efficacy } \\
\text { This validity / effectiveness are less well established by evidence or opinion }\end{array}$ \\
\hline Class III & There is no evidence for particular procedure \\
\hline
\end{tabular}

apheresis is not established and finally, the category IV where there is published evidence that demonstrates or suggests that apheresis is ineffective or even harmful (Tables 4-7) [21]. In category III clinical treatment decision should be individualized. There is also the category $\mathrm{P}$, designed for modalities still being tested or that have not been approved. This categorization is a model for clinical decision, without excluding patients who may have a small benefit [12].

\section{Conclusion}

Plasmapheresis has proven effectiveness in a large number of neurological diseases, and its main limitation, when properly indicated, is the availability of the procedure and adverse effects. There is limited research with control groups from an ethical point of view. Therefore, a greater number of clinical trials are necessary, including neurological disorders categorized as a group with still uncertain benefit, for lack of clinical evidence.

Table 4. Indications for Plasmapheresis therapy according to the American Society for Apheresis (ASFA) in 2013 (adapted - only neurological disorders).

Category I: first-line treatment.

\begin{tabular}{|c|c|}
\hline Category I & Degree \\
\hline Inflammatory demyelinating polyneuropathy, acute (GuillainBarre syndrome) & $1^{\mathrm{a}}$ \\
\hline Chronic inflammatory demyelinating polyradiculoneuropathy & 1B \\
\hline $\begin{array}{l}\text { Miastenia Gravis } \\
-\quad \text { Moderate-severe } \\
-\quad \text { Pre-thymectomy }\end{array}$ & $\begin{array}{l}1 \mathrm{~B} \\
1 \mathrm{C}\end{array}$ \\
\hline PANDAS (exacerbação) & 1B \\
\hline $\begin{array}{l}\text { Polyneuropathy paraproteinaemias } \\
\text { - } \quad \text { IgG/IgA } \\
\text { - } \quad \text { IgM }\end{array}$ & $\begin{array}{l}1 \mathrm{~B} \\
1 \mathrm{C}\end{array}$ \\
\hline Sydenham's chorea & 1B \\
\hline Fulminant Wilson's disease & $1 \mathrm{C}$ \\
\hline
\end{tabular}

Table 5. Indications for Plasmapheresis therapy according to the American Society for Apheresis (ASFA) in 2013 (adapted - only neurological disorders). Category II: secondline treatment.

\begin{tabular}{|l|l|}
\hline Category II & Degree \\
\hline Acute disseminated encephalomyelitis & 2C \\
\hline Lambert-Eaton myasthenic syndrome & 2C \\
\hline $\begin{array}{l}\text { Multiple sclerosis } \quad \quad \text { Acute inflammatory demyelinating disease of the CNS } \\
\text { Acute optic neuromyelitis }\end{array}$ & $1 \mathrm{~B}$ \\
\hline
\end{tabular}

CNS: Central Nervous System.

Table 6. Indications for Plasmapheresis therapy according to the American Society for Apheresis (ASFA) in 2013 (adapted - only neurological disorders). Category III: Paper not established yet.

\begin{tabular}{|l|l|}
\hline Category III & Degree \\
\hline $\begin{array}{l}\text { Inflammatory demyelinating polyneuropathy, acute (GuillainBarre syndrome) } \\
\text { Following intravenous immunoglobulin infusion }\end{array}$ & $2 \mathrm{C}$ \\
\hline $\begin{array}{l}\text { Multiple sclerosis } \\
-\quad \text { Progressive Chronicle }\end{array}$ & 2B \\
\hline $\begin{array}{l}\text { Optics Neuromyelitis - maintenance } \\
\text { Hard man syndrome }\end{array}$ & $2 \mathrm{C}$ \\
\hline $\begin{array}{l}\text { Chronic focal encephalitis (Rasmussen's encephalitis) } \\
\text { Paraneoplastic neurological syndromes }\end{array}$ & $2 \mathrm{C}$ \\
\hline $\begin{array}{l}\text { Polyneuropathy paraproteinemia } \\
\text { IgG/IgA/IgM }\end{array}$ & $2 \mathrm{C}$ \\
\hline
\end{tabular}

Table 7. Indications for Plasmapheresis therapy according to the American Society for Apheresis (ASFA) in 2013 (adapted - only neurological disorders).

Category IV: ineffective or harmful

\begin{tabular}{|l|l|}
\hline Category IV & Degree \\
\hline Amyotrophic lateral sclerosis & $1 \mathrm{C}$ \\
\hline
\end{tabular}




\section{References}

1. Cortese I, Chaudhry V, So YT, Cantor F, Cornblath DR, et al. (2011) Evidence-based guideline update: Plasmapheresis in neurologic disorders: report of the Therapeutics and Technology Assessment Subcommittee of the American Academy of Neurology. Neurology 76: 294-300. [Crossref]

2. Linker C (1983) Plasmapheresis in clinical medicine. West JMed 138: 60-69. [Crossref]

3. Fridey JL, Kaplan AA (2014) Therapeutic apheresis: indications and technique. Up To Date 1-15.

4. Weinstein R (2008) Therapeutic apheresis in neurological disorders: a survey of the evidence in support of current category I and II indications for therapeutic plasma exchange. J Clin Apher 23: 196-201. [Crossref]

5. Clark WF, Rock GA, Buskard N, Shumak K, LeBlond P, et al. (1999) Therapeutic plasma exchange: an update from the Canadian apheresis group. Ann Int Med 131: 453-462. [Crossref]

6. Lehmann HC, Hartung HP, Hetzel GR, Stüve O, Kieseier BC (2006) Plasma exchange in neuroimmunological disorders: part 2. Treatment of neuromuscular disorders. Arch Neurol 63: 1066-1071. [Crossref]

7. Yücesan C, Arslan Ö, Arat M, Yücemen N, Ayyildiz E, et al. (2007) Therapeutic plasma exchange in the treatment of neuroimmunologic disorders: review of 50 cases. Transfus Apheresis Sci 36: 103-107. [Crossref]

8. Latov N (2014) Diagnosis and treatment of chronic acquired demyelinating polyneuropathies. Nat Rev Neurol 10: 435-446. [Crossref]

9. Nogales-Gaete J, Valenzuela D, Liendo F, Vidal P, Gil G, et al. (2004) [Plasmapheresis in neurological diseases. Experience in 140 procedures in 47 patients]. Rev Med Chil 132: 295-298. [Crossref]

10. Hahn AF, Bolton CF, Pillay N, Chalk C, Benstead T, et al. (1996)Plasma-exchange therapy in chronic inflammatory demyelinating polyneuropathy. A double-blind, shamcontrolled, cross-over study. Brain 119:1055-1066. [Crossref]
11. Li Y, Arora Y, Levin K (2013) Myasthenia gravis: newer therapies offer sustained improvement. Cleve Clin J Med 80: 711-721. [Crossref]

12. Schwartz J, Winters JL, Padmanabhan A, Balogun RA, Delaney M, et al. (2013) Guidelines on the use of therapeutic apheresis in clinical practice-evidence-based approach from the Writing Committee of the American Society for Apheresis: the sixth special issue. J Clin Apher 28: 145-284. [Crossref]

13. Zhang L, Liu J, Wang H, Zhao C, Lu J, et al. (2014) Double filtration plasmapheresis benefits myasthenia gravis patients through an immunomodulatory action. $J$ Clin Neurosci 21: 1570-1574. [Crossref]

14. Lehmann HC, Hartung HP, Hetzel GR, Stüve O, Kieseier BC (2006) Plasma exchange in neuroimmunological disorders: Part 1: Rationale and treatment of inflammatory central nervous system disorders. Arch Neurol 63: 930-935. [Crossref]

15. Chhibber V, Weinstein R (2012) Evidence-based review of therapeutic plasma exchange in neurological disorders. Semin Dial 25: 132-139. [Crossref]

16. Rodriguez M, Karnes WE, Bartleson JD, Pineda AA (1993)Plasmapheresis in acute episodes of fulminant CNS inflammatory demyelination. Neurology 43: 1100-1104. [Crossref]

17. Jamshidian A, Gharagozloo M (2012) Can plasma exchange therapy induce regulatory T lymphocytes in multiple sclerosis patients? Clin Exp Immunol 168: 75-77. [Crossref]

18. Sato D, Callegaro D, Lana-Peixoto MA, Fujihara K; Brazilian Committee for Treatment and Research in Multiple Sclerosis (2012) Treatment of neuromyelitisoptica: an evidence based review. Arq Neuropsiquiatr 70: 59-66. [Crossref]

19. Munemoto M, Otaki Y, Kasama S, Nanami M, Tokuyama M, et al. (2011) Therapeutic efficacy of double filtration plasmapheresis in patients with anti-aquaporin-4 antibodypositive multiple sclerosis. J Clin Neurosci 18: 478-480. [Crossref]

20. Pohl D, Tenembaum S (2012) Treatment of acute disseminated encephalomyelitis. Curr Treatment Opin Neurol 14: 264-275. [Crossref]

21. Bocchi EA, Neto JAM (2001) Applying the principles of medicine based on evidence in assessment procedures and high cost drug programs.Arq Bras Cardiol 76: 339-342.

Copyright: (2016 Meneses de Oliveira FT. This is an open-access article distributed under the terms of the Creative Commons Attribution License, which permits unrestricted use, distribution, and reproduction in any medium, provided the original author and source are credited. 